University of Nebraska - Lincoln

DigitalCommons@University of Nebraska - Lincoln

Faculty Publications from the Harold W. Manter Laboratory of Parasitology

$10-1956$

\title{
Observations on Shipleya inermis Fuhrmann, 1908 (Cestoda: Acoleidae)
}

\author{
Marietta Voge \\ University of California - Los Angeles \\ Robert L. Rausch \\ University of Washington, rausch@u.washington.edu
}

Follow this and additional works at: https://digitalcommons.unl.edu/parasitologyfacpubs

Part of the Parasitology Commons

\footnotetext{
Voge, Marietta and Rausch, Robert L., "Observations on Shipleya inermis Fuhrmann, 1908 (Cestoda: Acoleidae)" (1956). Faculty Publications from the Harold W. Manter Laboratory of Parasitology. 587. https://digitalcommons.unl.edu/parasitologyfacpubs/587
}

This Article is brought to you for free and open access by the Parasitology, Harold W. Manter Laboratory of at DigitalCommons@University of Nebraska - Lincoln. It has been accepted for inclusion in Faculty Publications from the Harold W. Manter Laboratory of Parasitology by an authorized administrator of DigitalCommons@University of Nebraska - Lincoln. 
Voge \& Rausch in Journal of Parasitology (October 1956) v. 42, no. 5.

Copyright 1956, American Society of Parasitologists. Used by permission.

\title{
OBSERVATIONS ON SHIPLEYA INERMIS FUHRMANN, 1908 (CESTODA: ACOLEIDAE)
}

\author{
Marietta Voge and Robert Rausch \\ Department of Infectious Diseases, School of Medicine, University of California, Los Angeles; \\ and Arctic Health Research Center, Public Health Service, U. S. Department of Health, \\ Education and Welfare, Anchorage, Alaska
}

Shipleya inermis, described by Fuhrmann (1908) and redescribed by Baer (1940), is known from only few specimens. The first and only North American record of this species was published by Webster (1951), who reported the finding of 2 specimens in dowitchers. Examination of a large number of cestodes from dowitchers collected by one of us (Rausch), and of cestodes from the Helminthological Collection of the United States National Museum yielded specimens which are without doubt Shipleya inermis. However, some of our observations which are reported here do not agree with Baer's description. In particular, we are unable to agree with Baer (1940) that individuals of $S$. inermis are hermaphroditic.

We are grateful to Mr. Allen McIntosh, Zoological Division, Beltsville, Maryland, for the loan of cestodes from dowitchers; and to Dr. F. N. Hamerstrom, Plainfield, Wisconsin, who collected the dowitcher from Iowa.

\section{MATERIALS AND METHODS}

The cestodes on which our study is based were obtained from 7 specimens of dowitcher, Limnodromus spp.* as follows: U. S. N. M. Helm. Coll. No. 48930 from La Jolla, California, April, 1947 (1 cestode) ; U. S. N. M. Helm. Coll. No. 48953 from the same locality, March 1935 (2 cestodes) ; No. R1, from Bono, Lucas Co., Ohio, August, 1944 ( 1 cestode) ; No. R3, Ruthven, Iowa, July 1934 (2 cestodes); No. R014550 from 12 miles south Anchorage, Alaska, May 17, 1955 (2 cestodes); No. R3A from Tulugak Lake, Brooks Range, Alaska, May 31, 1949 (1 cestode); No. R2A from Tulugak Lake, Brooks Range, Alaska, May 31, 1949 (2 cestodes).

Formalin or AFA was used for fixation. The cestodes were in excellent state of preservation. They were stained as whole mounts with carmine or hematoxylin stains. Thick sections were stained with Ehrlich's hematoxylin. It should be stressed that all our specimens were sufficiently well stained to eliminate the possibility of incomplete observation.

\section{DESCRIPTION OF SPECIMENS}

In view of the controversial question regarding the location of male and female gonads in Shipleya inermis, it seemed desirable to describe separately the specimens obtained from each individual host.

Received for publication, June 25, 1956.

* According to Pitelka (1950), 2 species of Limnodromus occur in North America, viz. L. griseus (Gmelin) and L. scolopaceus Say. The birds utilized in this work were collected mainly during migration, and both species were probably represented. Since the birds were not preserved for study, specific determinations were not made. 
Voge \& Rausch in Journal of Parasitology (October 1956) v. 42, no. 5.

Copyright 1956, American Society of Parasitologists. Used by permission.

Host No. R2A contained 2 cestodes. One unbroken strobilar fragment $5 \mathrm{~cm}$ long and 2.3 $\mathrm{mm}$ in greatest width, containing only female gonads in mature proglottids (Fig. 1) followed by semi-gravid and gravid proglottids. For practical purposes the term "vagina" will be used to designate the organ in female strobilae which closely resembles the cirrus pouch and cirrus in male specimens. Vagina length is 765 microns in mature, and as much as 850 microns in gravid proglottids. The second specimen, a continuous strobila $1.9 \mathrm{~cm}$ long, measured $2.6 \mathrm{~mm}$ in greatest width, and consists of a scolex which had been deeply imbedded in the intestinal mucosa, and the strobila. Early immature proglottids contain the primordia of the cirrus pouch only. These are followed by segments which contain, in addition, a central primordium which eventually gives rise to a central mass of follicles. At this stage, the cirrus pouch is up to 850 microns long. No other gonadal structures are seen. Posterior to the region of clearly distinguishable follicles the proglottids increase in size and contain a central mass of fine granules which are the remnant of the follicular structures (Fig. 4). The granules eventually disappear. No trace of a uterus or of primordia of female gonads can be seen. Cirrus pouch length in these segments is as much as 900 microns. In all proglottids of this specimen, excepting the immature region, the cirrus pouch extends to the mid-line of the segment. This is not so in the specimen containing the female gonads.

No. 48953 also contained 2 cestodes. One of these is a fragment $1.8 \mathrm{~cm}$ long, containing the early immature and the mature region. Fully mature proglottids contain the female gonads. In early immature proglottids one observes the longitudinal excretory ducts and the primordia of the vagina. In mature proglottids $1.2 \mathrm{~mm}$ wide the vagina is 380 microns long. No testes are seen in this specimen. The second cestode is $3 \mathrm{~cm}$ long and about $1 \mathrm{~mm}$ in greatest width. The scolex (Fig. 3) is $1.2 \mathrm{~mm}$ wide and continuous with the remainder of the strobila. Sucker diameter is $272-300$ microns. Immature proglottids contain primordia of the cirrus pouch and more posteriorly a central mass which resolves into a group of closely approximated follicles. At this stage, proglottids are about $1 \mathrm{~mm}$ wide and contain a fully developed cirrus pouch 552-640 microns long, extending beyond the mid-line of the segments (Fig. 2). Proglottids of similar size in the female strobila described above appear completely undifferentiated, except for excretory and muscular systems.

Host No. R3 contained 2 cestodes: One whole worm $6 \mathrm{~cm}$ long with a greatest width of 5 $\mathrm{mm}$ (contracted segments) and a scolex $1.37 \mathrm{~mm}$ wide, with suckers 357 microns in diameter. Immature proglottids contain the primordia of the female gonads and are followed by mature proglottids with well developed female gonads. The gravid segments contain the uterus and the vagina which is as much as 850 microns in length. Testes are not present in this specimen. The second cestode without scolex is $1.9 \mathrm{~cm}$ long. A central mass of follicles is present in anterior proglottids. In the posterior third of this strobila the follicles gradually disintegrate and eventually disappear. No primordia or traces of female gonads are seen in this specimen. The cirrus pouch extends to the mid-line of each segment and attains a length of 850 microns in the region where the follicles have disappeared.

No. 014550 contained a strobilar fragment including immature and mature regions. Mature proglottids contain a central mass of follicles and the cirrus pouch extends to the mid-line of the segment. No other gonadal structures are present. A second fragment comprising immature and mature proglottids contains female gonads only.

No. R3A contained one cestode. The strobila is $7 \mathrm{~cm}$ long and $4.5 \mathrm{~mm}$ in greatest width (contracted segments). Only female gonads are observed. The vagina attains a length of 680 microns in semi-gravid proglottids.

U.S.N.M. 48930 contained a fragment $1.5 \mathrm{~cm}$ long with early immature proglottids, mature proglottids with a central mass of follicles and a cirrus pouch, followed by segments in which the follicles had disappeared. No trace of female gonads was seen.

Host No. R1 contained 1 intact cestode $8 \mathrm{~cm}$ long and $3.5 \mathrm{~mm}$ in greatest width, with a scolex diameter of 900 microns and a sucker diameter of 250 microns. The primordia of the female gonads are seen about $1.5 \mathrm{~mm}$ posterior to the scolex. No testes are present. Mature proglottids contain the female gonads. In semi-gravid proglottids, vagina length is 640 microns. Onchosphere diameter in gravid proglottids is $30-34 \times 38-40$ microns.

\section{DISCUSSION}

Every segment of our material was carefully examined for the presence of both male and female gonads. From our observations we are convinced that our specimens represent entirely male or entirely female individuals of the same species of cestode. That this species is indeed Shipleya inermis Fuhrmann, 1908, is an as- 
Voge \& Rausch in Journal of Parasitology (October 1956) v. 42, no. 5.

Copyright 1956, American Society of Parasitologists. Used by permission.

sumption based on the close agreement of our observations with the original description and, with the exception of testis location, to Baer's description (1940).

When Fuhrmann (1908) described Shipleya inermis from Galinago gigantea, his diagnosis of the genus was as follows (authors' translation):

"Acoleinae with scolex lacking rostellum or hooks. Male genital pores alternating regularly. The conical penis armed with large hooks. Vitelline gland dorsal to ovary. The only remnant of the vagina is a small seminal receptacle near the female gonad. Uterus at first ringshaped, very much ramified." Fuhrmann states (p. 72) that the testes were not seen and that they must occur without doubt in the early segments and then quickly disappear. He further states (p. 73) that the finer structure of the ovary could not be studied because of the state of preservation of the specimen. Baer (1940) also comments on the poor preservation of the original types. In young proglottids, the uterus is ring-shaped as in Gyrocoelia (Fuhrmann, p. 73). However, Fuhrmann's figure (p. 71) shows that the uterus does not form a complete ring.

Baer (1940) describes "several specimens" from Capella delicata as Shipleya inermis. He does not state whether or not his specimens were fragmented. His description does not include strobilar or scolex size. While Fuhrmann did not see the testes in his material, Baer describes 20-25 testes closely packed near the median end of the cirrus pouch. Our observations are in agreement with this statement. However, with regard to the position of the testes in the strobila, he states (p. 180): "The internal anatomy of this worm is peculiar in many ways and especially in that the anterior part of the strobila is entirely male, no female glands being visible although the uterus and receptaculum seminis are present." His figure 17 (p. 181) shows a transverse section of a male segment containing the cirrus pouch and testes as well as a structure labelled as receptaculum seminis. The uterus is not shown.

It appears that Baer was dealing with a species very much like Shipleya inermis but hermaphroditic, which is unlikely, or that his specimens were fragmented so that the sequence of development within the strobila could not be determined with accuracy. The male specimens studied by us are much shorter than the female specimens, and the male mature proglottids are as a rule smaller. This may lead to the belief that one is dealing with anterior portions of a strobila which subsequently contains the female gonads. Baer also states that "the testes have completely disappeared in the segments in which the female genitalia are formed." We have examined several intact specimens which contained only female genitalia.

Inamdar (1942) described Shipleya farrani from Himantopus himantopus in India. The scolex of his specimen bears a "papilla" 160 microns long which, judging from his illustration, looks very much like a rostellum. The genital pores are described as alternating irregularly, and the testes are seen anterior to the ovary in a few mature segments. The ovary is bilobed and the uterus ring-shaped. The considerations presented here cast doubt on the relationship of Inamdar's species to Shipleya. Not having seen his specimens, we defer decision on the allocation of Shipleya farrani.

Burt (1939) stressed the close resemblance between the dioecious cestode Infula and the genera Gyrocoelia and Shipleya. In view of the information presented above, the relationship between Shipleya and Infula is even more striking. As far as can be determined, the 2 major differences are the presence of a rostellum and a ring-shaped uterus in Infula, and the absence of a rostellum in Shipleya which 
Voge \& Rausch in Journal of Parasitology (October 1956) v. 42, no. 5.

Copyright 1956, American Society of Parasitologists. Used by permission.

has a horseshoe-shaped uterus. It is questionable whether Infula deserves separate generic status on the basis of these differences. Unless further evidence to the contrary is presented, the species of Infula should probably be assigned to the genus Shipleya.

\section{Shipleya Fuhrmann, 1908}

Revised generic diagnosis: Acoleidae with a large scolex. Sexes separate. Testes in several dorso-ventral layers. Cirrus prominent, armed with numerous large hooks. Female genitalia median. Yolk gland postero-dorsal to ovary. A large receptaculum seminis present. Uterus horseshoe-shaped with anterior diverticulum, and developing numerous side branches. Distal end of vagina very similar to cirrus pouch in male. Adults in charadriiform birds.

Type species: Shipleya inermis Fuhrmann, 1908.

\section{Shipleya inermis Fuhrmann, 1908}

Specific diagnosis: Scolex without rostellum or hooks, diameter range $0.9-1.37 \mathrm{~mm}$; sucker diameter range $250-357$ microns. Genital pores alternating regularly. Excretory system consists of 2 pairs of longitudinal ducts, both with cross-connections in each proglottid.

Male: Total length $3 \mathrm{~cm}$, greatest width $2.6 \mathrm{~mm}$. Mature proglottids with about 25 closely approximated testes in at least 2 dorso-ventral layers, nearly in center of proglottid. Cirrus pouch extending to or beyond mid-line of proglottid; cirrus pouch length range 552-900 microns. Cirrus armed with numerous large hooks. A thread-like, short connection between proximal end of cirrus pouch and testes is present. Testes disintegrate in posterior portion of strobila.

Female: Total length up to $8 \mathrm{~cm}$; strobila greatest width range $2.3-3.5 \mathrm{~mm}$ in relaxed proglottids. Female gonads median. Ovary with many slender lobes. Seminal receptacle and shell gland present. Uterus in early mature proglottids horseshoe-shaped enclosing the female gonads, developing numerous side branches eventually filling proglottid. Vagina not extending to mid-line of proglottid, length range $380-850$ microns, with cirrus-like organ as in male armed with hooks up to 30 microns long.. Eggs measure $30-32 \times 51-57$ microns.

\section{Type host: Gallinago undulata gigantea}

Other hosts: Gallinago delicata, Limnodromus spp.

\section{SUMMARY}

Eleven specimens of Shipleya inermis Fuhrmann, 1908, are described from 7 dowitchers in North America. Evidence is presented that this cestode is dioecious. Revised generic and specific diagnoses are included. The relationships of the species of Shipleya, and of the genera Shipleya and Infula are discussed.

\section{References Cited}

BAer, J. G. 1940 Some avian tapeworms from Antigua. Parasitol. 32: 174-197.

BurT, D. R. R. 1939 On the cestode family Acoleidae, with a description of a new dioecious species, Infula burhini gen. et sp. nov. Spolia Zeylanica 21: 195-208.

Fuhrmann, O. 1908 Nouveaux tenias d'oiseaux. Rev. Suisse Zool. 16: 27-73.

INAmpar, N. B. 1942 A new species of avian cestode from India. J. Univ. Bombay (New Series) $11: 77-81$.

Pitelka, F. A. 1950 Geographic variation and the species problem in the shore-bird genus Limnodromus. Univ. Cal. Publ. Zool. 50: 1-108.

Webster, J. D. 1951 Systematic notes on North American Acoleidae (Cestoda). J. Parasitol. 37: 111-118.

\section{Explanation of Plate}

(All drawings made with the aid of a camera lucida.)

FIGURE 1. Shipleya inermis. Female mature proglottid.

Figure 2. S. inermis. Male mature proglottid.

Figure 3. S. inermis. Scolex.

Figure 4. S. inermis. Old male proglottid. The testes have disintegrated. A few granules only remain. 
Voge \& Rausch in Journal of Parasitology (October 1956) v. 42, no. 5.

Copyright 1956, American Society of Parasitologists. Used by permission.

\section{Plate I}
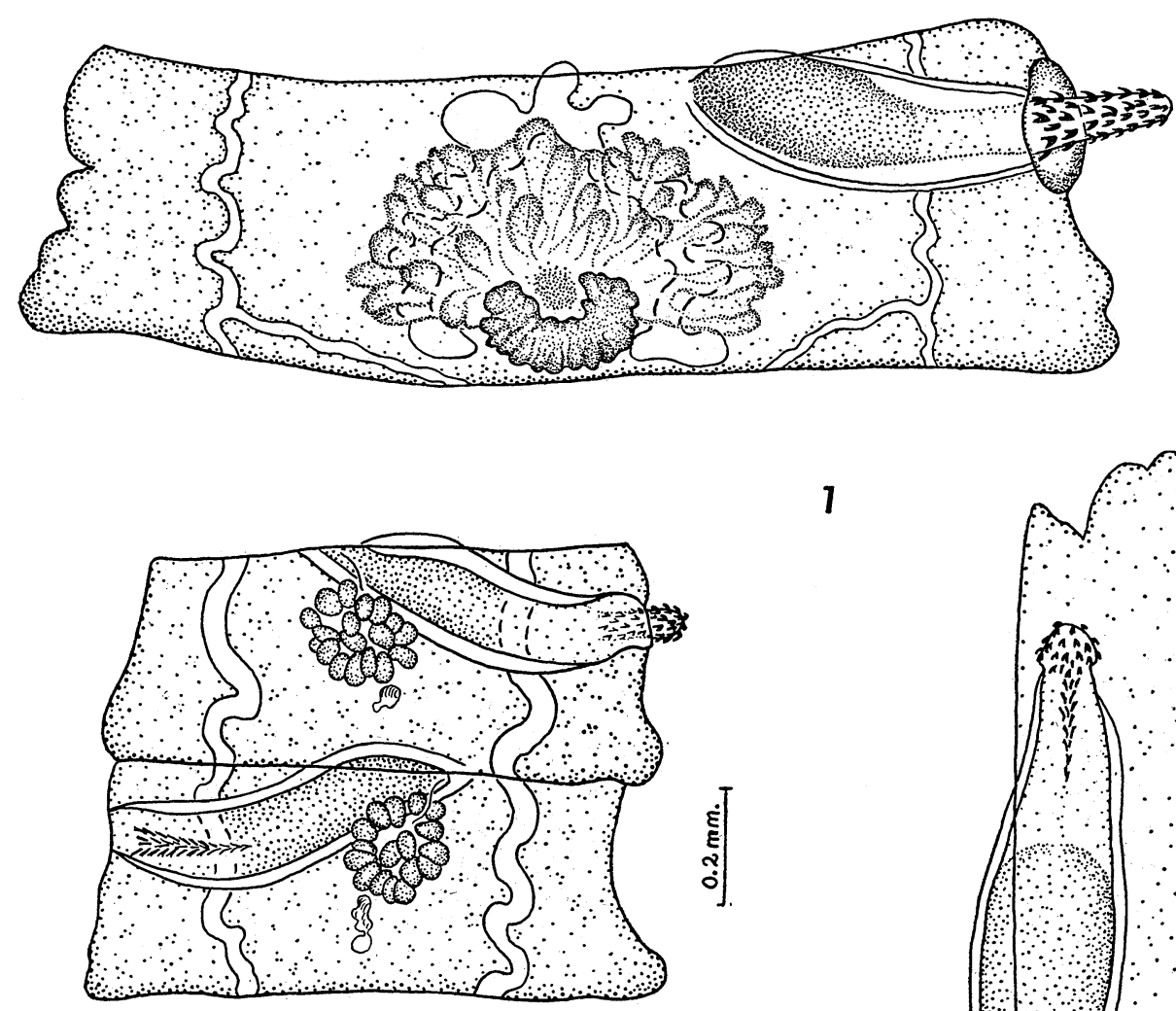

1

2
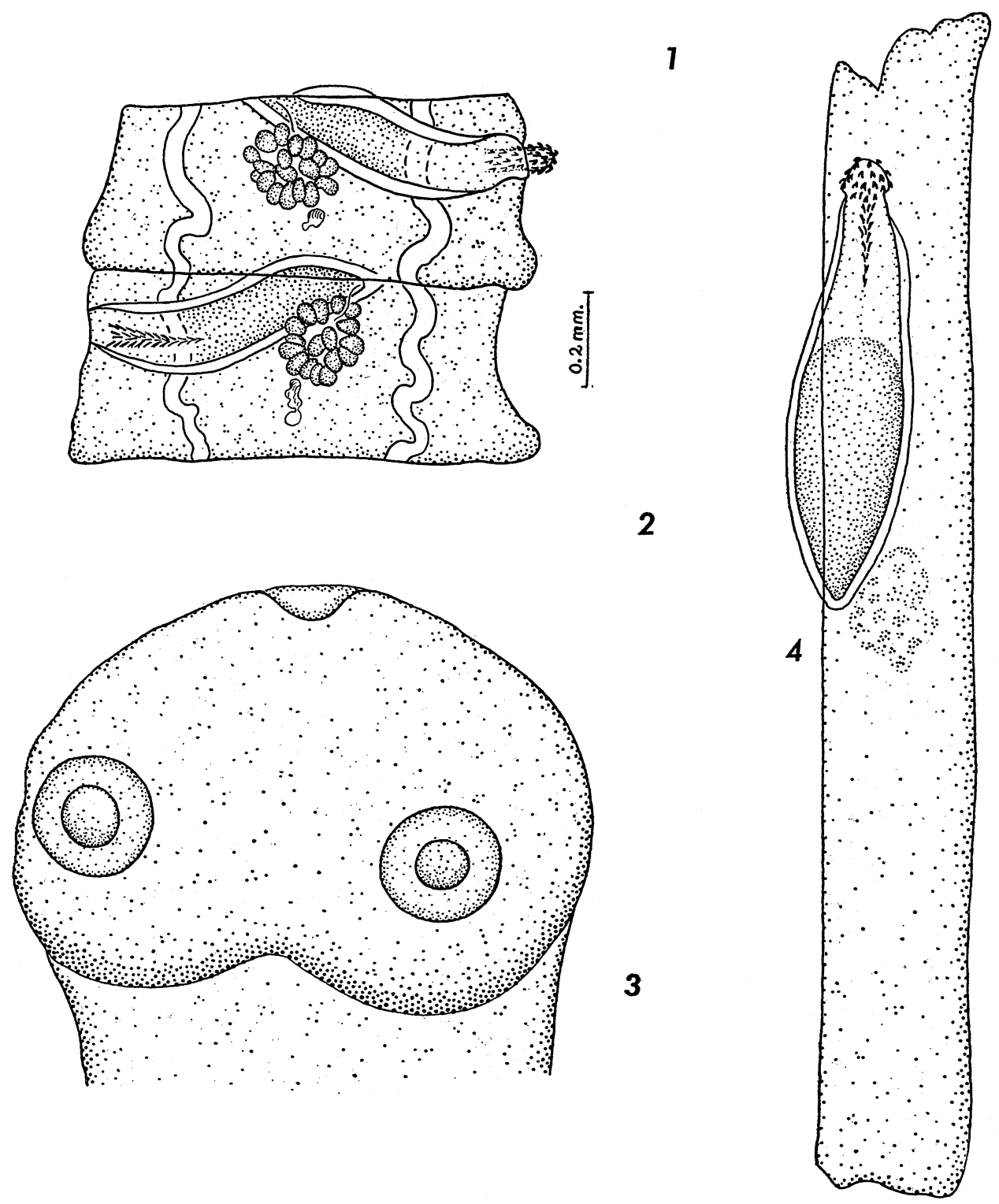